\title{
O CONHECIMENTO DE PROFESSORES DOS ANOS INICIAIS DO ENSINO FUNDAMENTAL SOBRE FRAÇÃO: implicações para o ensino
}

\author{
THE KNOWLEDGE OF ELEMENTARY SCHOOL TEACHERS \\ ABOUT FRACTION: implications for teaching
}

\section{EL CONOCIMIENTO DE PROFESORES DE LOS AÑOS INICIALES DE LA ENSEÑANZA FUNDAMENTAL SOBRE FRACCIÓN: implicaciones para la enseñanza}

\author{
Lidiane Chaves Zeferino \\ Mestra em Educação pela Universidade Federal de São Paulo (UNIFESP) \\ Guarulhos, SP - Brasil \\ lidianeczeferino@gmail.com
}

\author{
Vanessa Dias Moretti \\ Professora Doutora da Universidade Federal de São Paulo (UNIFESP) \\ Guarulhos, SP - Brasil \\ vanessa.moretti@unifesp.br
}

\begin{abstract}
Resumo: Neste artigo propomos apresentar parte dos resultados de uma pesquisa que buscou investigar questões relacionadas ao conhecimento do professor, ao seu processo de aprendizagem e à organização do ensino de matemática. Assim, foi tomada como questão de investigação "como a organização do ensino do conceito de número racional, na sua representação fracionária, a partir das contribuições da Teoria Histórico-Cultural e, em particular, da Atividade Orientadora de Ensino, influencia e é influenciada pelo desenvolvimento do pensamento teórico do professor que ensina matemática no quarto e quinto ano do ensino fundamental?". Ou seja, como o conhecimento e a compreensão que o professor tem sobre fração impacta a forma como esse professor organiza o seu ensino. Como princípio orientador da investigação utilizou-se o experimento didático com professores dos quartos e quintos anos do ensino fundamental. Os resultados dessa pesquisa reforçam que a aprendizagem docente pode resultar de uma constante busca mediada de novas ações que reflitam novas apropriações teóricas do professor na articulação entre a teoria e a prática na organização do ensino de matemática. No trabalho docente, essa transformação se dá por meio da apropriação do conhecimento científico do conceito e na organização do ensino que passa a ser objetivada em novas práticas.
\end{abstract}

Palavras-Chave: Teoria Histórico-Cultural. Fração. Aprendizagem docente. Atividade de Ensino. Pensamento Teórico.

Abstract: In this article we propose to present part of the results of a research that sought to investigate questions related to the knowledge of the teacher, to his learning process and to the organization of mathematics teaching. Thus, it was taken as a research question "how the organization of the teaching of the concept of rational number, in its fractional representation, from the contributions of Historical-Cultural Theory and, in particular, Teaching Guidance Activity, influences and is influenced by development of the theoretical thought of the teacher who teaches mathematics in the fourth and fifth year of elementary school? " That is, how the knowledge and understanding that the teacher has about fraction impacts the way that teacher organizes his teaching. As a guiding principle of the research was used the didactic with teachers of the fourth and fifth years of elementary school. The results of this research reinforce that teacher learning can result from a constant mediated search for new actions that reflect new theoretical appropriations of the teacher in the articulation between theory and practice in the organization of mathematics teaching. In the teaching work, this transformation happens through the appropriation of the scientific knowledge of the concept and in the organization of teaching that happens to be objectified in new practices.

Keywords: Historical-Cultural Theory. Fraction. Teaching learning. Teaching Activity. Theoretical Thought.

Resumen: En este artículo proponemos presentar parte de los resultados de una investigación que buscó investigar cuestiones relacionadas con el conocimiento del profesor, su proceso de aprendizaje y la organización de la enseñanza de matemáticas. "¿ Así, se tomó como cuestión de investigación como la organización de la enseñanza del concepto de número racional, en su representación fraccionaria, a partir de las contribuciones de la Teoría Histórico-Cultural y, en particular, de la Actividad Orientadora de Enseñanza, influye y es influenciada por el trabajo desarrollo del pensamiento teórico del profesor que enseña matemáticas en el cuarto y quinto año de la enseñanza fundamental?". Es decir, cómo 
el conocimiento y la comprensión que el profesor tiene sobre fracción impacta la forma en que ese profesor organiza su enseñanza. Como principio orientador de la investigación se utilizó el experimento didáctico, el cual ocurrió en la forma de un curso de extensión orientado a la formación continuada de profesores de las habitaciones y quintos años de la Enseñanza Fundamental. Los resultados de esta investigación refuerzan que el aprendizaje docente puede resultar de una constante búsqueda mediada de nuevas acciones que reflejen nuevas apropiaciones teóricas del profesor en la articulación entre la teoría y la práctica en la organización de la enseñanza de matemáticas. En el trabajo docente, esa transformación se da por medio de la apropiación del conocimiento científico del concepto y en la organización de la enseñanza que pasa a ser objetivada en nuevas prácticas.

Palabras Clave: Teoría Histórico-Cultural. Fracción. Aprendizaje docente. Actividad de Enseñanza. Pensamiento Teórico.

\section{INTRODUÇÃO}

O conceito de número racional, na sua representação fracionária, costuma representar desafios para alunos e professores ao longo da Educação Básica. Em especial, nos anos iniciais do ensino fundamental não é raro o relato de dificuldades dos professores para o ensino desse conceito (MAGINA; CAMPOS, 2008). Partindo desse contexto, esse texto apresenta parte dos resultados de uma pesquisa que buscou pesquisar questões relacionadas ao conhecimento do professor, ao seu processo de aprendizagem e à organização do ensino de matemática. Assim, foi tomada como questão de investigação "como a organização do ensino do conceito de número racional, na sua representação fracionária ${ }^{1}$, a partir das contribuições da Teoria Histórico-Cultural (VIGOTSKI, 2004; 2007; 2010) e, em particular, da Atividade Orientadora de Ensino (MOURA, 1996), influencia e é influenciada pelo desenvolvimento do pensamento teórico do professor que ensina matemática no quarto e quinto ano do ensino fundamental?" Ou seja, como o conhecimento e a compreensão que o professor tem sobre o conceito de fração impacta a forma como esse professor organiza o seu ensino.

A seguir apresentaremos alguns dos elementos essenciais que subsidiam a fundamentação teórica da pesquisa, a metodologia de coleta e análise de dados e, por fim, a análise de um dos episódios (MOURA, 2004) da pesquisa desenvolvida que demostra alguns movimentos de formação do pensamento teórico do professor - reflexão, análise e planificação das ações - os quais, evidenciaram a tomada de consciência, identificação e compreensão dos elementos que constituem o conceito de fração estudado e sobre suas ações de ensino (DAVIDOV, 1988).

\section{PRESSUPOSTOS TEÓRICOS DA PESQUISA}

Como fundamentação teórica da pesquisa optamos por utilizar as lentes da Teoria HistóricoCultural, advinda das produções de Vigotski (2007; 2010), Leontiev (1978), Davidov (1982; 1988), entre outros, por compreendermos que esse referencial contribui de forma significativa no estudo dos processos de desenvolvimento humano e da formação de sua individualidade, aqui projetada no trabalho docente e nas ações e necessidades do professor que ensina matemática. Dessa forma, é importante conhecer desde a origem das ações docentes até a apropriação do conhecimento matemático, os motivos da atividade e quais sentidos lhes são conferidos, e como esses favorecem o desenvolvimento do pensamento teórico. A Teoria Histórico-Cultural nos auxilia a compreender o processo de aprendizagem docente e a estabelecer elementos que favoreçam a organização do ensino. Como afirmam Mello e Lugle (2014) a Teoria Histórico-Cultural:

[...] parte do pressuposto de que o ser humano é um ser de natureza social, o que significa dizer que suas qualidades humanas - as capacidades, as habilidades e as aptidões, ou em outras palavras, sua inteligência e personalidade - são aprendidas. (MELLO; LUGLE, 2014, p. 263).

Compreende-se assim, a apropriação do conhecimento como um fenômeno ativo, o ser humano e sua humanidade, como produtos da sua história, criada pelos próprios seres humanos ao longo da sua trajetória. Segundo Moretti e Moura (2011), se

\footnotetext{
1 Ao longo do texto nos referiremos ao Conceito de Fração como forma simplificada de referenciar o conceito de Número Racional em sua representação fracionária.
} 
[...] dentro da perspectiva histórico-cultural, o homem se constitui pelo trabalho, entendendo esse como atividade humana adequada a um fim e orientada por objetivos, então o professor constitui-se professor pelo seu trabalho - a atividade de ensino - ou seja, o professor constitui-se professor por meio da atividade de ensino. Em particular, ao objetivar a sua necessidade de ensinar e, consequentemente, de organizar o ensino para favorecer a aprendizagem. (MORETTI e MOURA, 2011, p.443).

Por isso, conceber a atividade docente como um trabalho, a partir da concepção presente na obra de Marx e Engels (1876, p. 04) significa compreender que "o trabalho é a condição básica e fundamental de toda a vida humana. $\mathrm{E}$ em tal grau que, até certo ponto, podemos afirmar que 0 trabalho criou o próprio homem". Desse modo, o trabalho se objetiva respondendo às necessidades que foram surgindo na relação com seu ambiente, alterando a natureza e a si próprio. Como resultado desse processo, o homem por meio do trabalho, passa a controlar seu comportamento, da mesma forma que domina a natureza (ENGELS, 1975).

Ao entender que o ser humano se constitui nas relações que estabelece com o mundo físico e social, tendo como propósito atender as suas necessidades, o conceito de atividade emerge como aquele que permite a compreensão do desenvolvimento do professor em unidade com o processo educativo que, por sua vez, se desdobra no desenvolvimento humano. Como destacam Rigon, Asbahr e Moretti (2010):

A educação é entendida, na perspectiva teórica que assumimos como uma via para o desenvolvimento psíquico e principalmente humano, e não como mera aquisição de conteúdos ou habilidades específicas. E é com base nesse posicionamento que afirmamos a necessidade da presença da educação sistematizada em todas as fases do desenvolvimento, dado que ela permite uma organização consciente dos processos de formação dos indivíduos, via organização intencional de um ensino que permita aos sujeitos a apropriação de conhecimentos, de habilidades e de formas de comportamentos produzidos pela humanidade. (RIGON; ASBAHR; MORETTI, 2010, p. 29).

Compreender a formação docente como processo de aprendizagem nos conduz ao conceito da formação humana como um processo que promove o desenvolvimento, Moretti e Moura (2010, p. 347) ressaltam "que é no trabalho docente, ao desenvolver ações intencionais que tenham por objetivo dar conta dos desafios cotidianos do ensinar, que o professor constitui-se professor". Assim, a aprendizagem docente deve ser resultado de um constante movimento entre a atividade teórica e a atividade prática, como afirma Ribeiro (2011)

[...] o sujeito vai se formando professor no movimento da atividade teórica e da atividade prática, por meio do qual a teoria vai iluminando a prática e a prática vai fundamentando a teoria, rumo a constituição do pensamento teórico do professor sobre a docência. (RIBEIRO, 2011, p. 28).

Dessa forma, o professor em sua atividade tem como foco principal favorecer o desenvolvimento dos estudantes em direção à apropriação do conhecimento produzido historicamente, mesmo que para a concretização desse objetivo passe pela necessidade de rever sua prática, buscando novas maneiras de trabalhar a articulação entre a teoria e a prática, principalmente na organização do ensino de Matemática. Como afirma Moretti (2011):

A aprendizagem da docência em Matemática (...) não é uma aprendizagem possível apenas no âmbito de reflexões teóricas. Aprender a ser professor e, particularmente, aprender a ensinar matemática, passa por deparar-se com o desafio e a necessidade de organizar o ensino para favorecer a aprendizagem das crianças. (MORETTI, 2011, p. 387)

Assim, partimos do princípio que a aprendizagem docente, ao ter o seu alicerce em uma teoria que investiga o processo de aprendizagem, pode favorecer a organização do ensino e potencializar momentos de análises, reflexões e planificações das ações docentes (DAVIDOV, 1988). A Teoria Histórico-Cultural é uma abordagem que explicita uma educação promotora do desenvolvimento 
humano, porque se aprofunda nos estudos das questões relacionadas ao processo de apropriação de conhecimento e desenvolvimento humano.

No âmbito educacional, apoiando-nos nos pensamentos de Vigotski e Davidov, podemos considerar o espaço escolar como o mais privilegiado para a apropriação dos conhecimentos científicos historicamente construídos, favorecendo o desenvolvimento de formas complexas de pensamento. Nesse contexto, compreender o conhecimento do professor sobre o conceito de fração e sua relação com a organização do ensino, passa por compreender o processo de desenvolvimento do pensamento teórico do docente.

\subsection{Desenvolvimento do Pensamento Teórico}

Aqui nos atentaremos a discutir o que Davidov contempla em seu estudo sobre o pensamento, a consciência, a estrutura da atividade e, em especial, o estudo sobre a classificação do pensamento humano em: pensamento empírico e pensamento teórico.

Davidov (1988), assim como seus antecessores, ressalta que o trabalho é a principal base do conhecimento humano, sendo considerada por ele a atividade objetal-prática. Esse autor destaca a importância de o professor compreender o seu trabalho como atividade principal, uma vez que ao conceber a realidade em forma de conceito, caminhamos em direção ao pensamento teórico. Como afirma Davidov:

O pensamento teórico é o processo de idealização de um dos aspectos da atividade objetivo -prático, a reprodução, nela, das formas universais das coisas. Tal reprodução tem lugar na atividade laboral das pessoas como peculiar experimento objetivo-sensorial. Logo, este experimento adquire cada vez mais, um caráter cognoscitivo, permitindo às pessoas passarem, com o tempo, a realizar os experimentos mentalmente. (DAVÍDOV, 1988, p. 125)

Quando o professor toma consciência da fundamental importância de suas ações docentes, acontecem mudanças essenciais da atividade surgindo a possibilidade de que o pensamento empírico possa dar lugar ao pensamento teórico, uma vez que esse movimento relaciona-se à análise do processo de formação de sua atividade e de sua consciência (DAVIDOV, 1988). Como afirma Rosa (2012):

As fontes da consciência estão na relação do homem com a realidade, em sua vida social. Esta constitui a fonte das formas mais complexas da atividade consciente do ser humano. Em cada estágio de desenvolvimento lhe é inerente uma atividade principal e sobre essa base surgem e se formam novas estruturas psicológicas. (ROSA, 2012, p. 41)

Estudos como os de Catalani (2002), Bernardes (2006), Moretti (2007), Rosa (2012), Amorim (2015) apresentam alguns elementos que são extremamente importantes na realização das ações docentes, sendo um deles o trabalho pautado na organização do ensino e o domínio dos conhecimentos específicos acerca do trabalho que exerce. Como apontam Souza e Resende (2013, p. 7) "Na sociedade, o professor é quem assume essa tarefa de ser o organizador do processo educacional ao idealizar as atividades de ensino de forma intencional e é, nesse sentido, que o espaço escolar passa a ser valorizado nessa abordagem".

Como destaca Davidov em seus estudos, a apropriação do pensamento teórico possibilita ao sujeito condições de compreender novos significados para o seu meio podendo modificar a sua realidade e permitindo a ele, transformar a forma e o conteúdo do seu pensamento. Caminho que o professor deve percorrer para que ocorra a mudança no tipo de pensamento, do pensamento empírico para desenvolver o pensamento teórico. Descreve o pensamento empírico como o processo de pensamento que se limita

1) À comparação dos dados sensoriais concretos com a finalidade de separar os traços formalmente gerais e realizar sua classificação; 2) à identificação dos objetos sensoriais concretos com finalidade de sua inclusão em uma ou outra classe. (DAVÍDOV, 1988, p. 105)

Cedro, Moraes e Rosa (2010), afirmam que: 
O pensamento empírico possibilita ao sujeito uma atividade cognitiva que the assegure a separação dos atributos dos objetos ou fenômenos e sua designação, incluindo aí aqueles que em determinado momento não são possíveis de serem observados e que somente podem ser conhecidos indiretamente por meio de deduções. (CEDRO; MORAES; ROSA, 2010, p. 73).

Davidov (1988), em seus estudos salienta que o conhecimento teórico deve ser considerado como a principal questão da atividade de aprendizagem. Os sujeitos se apropriam do conhecimento teórico durante a realização dos diferentes tipos de atividades de aprendizagem nas quais estão inseridos. No caso dos professores, ocorre durante a atividade de ensino. Para esse autor, o pensamento teórico opera com o próprio conceito, como frisam Cedro, Moraes e Rosa (2010)

\footnotetext{
[...] os conceitos surgem não como simples representações gerais, mas sim como um modo de atividade psíquica do sujeito, que permite a ele a reprodução do objeto idealizado e, consequentemente, do seu sistema de relações, o qual na sua unidade reflete a universalidade ou a essência do movimento do objeto ou fenômeno. Portanto, o conceito constitui ao mesmo tempo a forma do reflexo do objeto e o meio da sua reprodução e estruturação mental. (CEDRO; MORAES; ROSA, 2010, p. 74- 75).
}

Davidov (1988) destaca ainda que o pensamento teórico está estritamente relacionado aos conceitos científicos e seu objeto são a integridade e a compreensão do sistema. O pensamento teórico objetiva a ascensão do abstrato ao concreto. Já o pensamento empírico, funciona mediante a identificação dos objetos sensoriais concretos e a comparação dos dados sensoriais concretos, ou seja, está voltado para a exteriorização e classificação dos objetos.

Davidov defende que a educação escolar deve ter como objetivo central desenvolver o pensamento teórico, o que assim, daria outra dimensão para pensamento empírico. Segundo esse autor, o ambiente escolar pode se constituir com espaço privilegiado para o desenvolvimento 0 pensamento teórico nos sujeitos. Isso porque é no ambiente escolar que o docente pode pôr em prática, de forma intencional e orientada, um ensino que promova o desenvolvimento dos conceitos científicos e vise à superação da escola tradicional (DAVIDOV, 1987, 1988), compreendida como aquela na qual dominam métodos intuitivos, cujos conhecimentos estão apenas vinculados à dimensão utilitária e empírica dos conceitos, "absolutamente insuficiente para assimilar o espírito autêntico da ciência contemporânea e os princípios de uma relação criativa, ativa e de profundo conteúdo em face da realidade" (DAVIDOV, 1987, p. 144).

Ressalta-se assim, a importância da organização do ensino que favoreça o desenvolvimento do pensamento teórico de todos os atores envolvidos no processo educacional. Por outro lado, justifica-se compreendermos a relação entre o conhecimento teórico do professor sobre o conceito e as implicações para a organização do ensino.

A importância da organização do ensino pode ser compreendida a partir dos estudos de Vigotski (2001), quando o autor afirma que a aprendizagem não é em si mesma o desenvolvimento, mas uma correta organização da aprendizagem do indivíduo é que conduz ao desenvolvimento psíquico e a aprendizagem é um momento intrinsecamente necessário e universal para que se desenvolvam no indivíduo as características humanas não naturais, mas formadas historicamente. Rosa (2012) destaca o desafio do professor em organizar o ensino, superando uma organização fundamentada apenas no conhecimento empírico para uma organização do ensino que favoreça desenvolvimento do pensamento teórico, visto que esse processo se inicia no movimento da aprendizagem docente.

Nessa direção, Moraes (2008) e Ribeiro (2011) investigaram a formação do pensamento teórico no movimento da aprendizagem docente, as quais explicitam o desenvolvimento dos elementos constituintes do pensamento teórico apresentados nos estudos de Davidov (1988): a análise, reflexão e planificação teórica das ações. Moraes (2008) avaliou o processo de apropriação dos conhecimentos matemáticos em movimento no desenvolvimento do pensamento teórico, buscando compreender a intervenção pedagógica como promotora do desenvolvimento humano, função essencial da escola. Já Ribeiro (2011) investigou a apropriação de elementos constitutivos de um modo geral de organização do ensino por futuros professores de matemática no desenvolvimento das disciplinas de Prática de Ensino e de Estágio.

Retomando a questão inicial de investigação, ou seja, como o conhecimento e a compreensão que o professor tem sobre o conceito de fração impacta a forma como esse professor organiza o seu 
ensino e, tomando como referência as pesquisas de Ribeiro (2011) e Moraes (2008) nossa análise evidenciou o movimento de análise, reflexão e planificação no desenvolvimento do pensamento teórico dos professores o que pôde ser observado durante as situações desencadeadoras de aprendizagem estruturadas na organização do ensino de frações.

\subsection{0 conceito de Fração}

A partir de relatos históricos (CARAÇA, 1989) podemos afirmar que as primeiras ideias de números racionais na sua representação fracionários surgiram da necessidade humana de medir. Tomando as premissas da perspectiva histórico-cultural, torna-se fundamental ao professor considerar tal contexto histórico ao planejar o ensino do conceito de fração. Segundo Rosa et al. (2013a), é fundamental que o professor planeje atividades para desenvolver o conceito com a base teórica histórica, significando-o aritmeticamente, algebricamente e geometricamente. É, portanto, importante que o aluno construa e observe a transformação da sociedade e da tecnologia durante o desenvolvimento humano, vislumbrando a necessidade de aprimorar a notação, a representação e os instrumentos, para concluírem a forma atual que estes se apresentam, bem como sua necessidade social. Como afirma Moretti (2007), “[...] compreender a essência das necessidades que moveram a humanidade na busca de soluções que possibilitaram a construção social e histórica dos conceitos é parte do movimento de compreensão do próprio conceito". (MORETTI, 2007, p. 97).

Tendo como base teórica a Teoria da Atividade, na qual a necessidade deve coincidir com o motivo para, dessa forma, ocorrer à aprendizagem do conceito, os estudantes, ao perceberem a necessidade e vincular a produção historicamente produzida com situações da realidade, vão se apropriar do conceito conseguindo resolver situações que a vida em sociedade exige. Ao mesmo tempo, ao refletir coletivamente sobre a necessidade humana que produziu o conceito e seus efeitos na vida social, o professor estará abordando o conteúdo de forma humanizadora e crítica, construindo o conteúdo junto de seus alunos, possibilitando, dessa forma, o desenvolvimento do pensamento teórico.

Entender a matemática como um conhecimento que a humanidade se apropriou ao longo da história permite-nos repensar como devemos ensinar. Segundo Moura (1996):

A matemática não é uma produção linear, não surgiu de imediato como um corpo de conhecimento formalmente organizado, mas foi e continua sendo elaborada em diferentes contextos históricos na interação do homem com o ambiente físico e cultural para atender as suas múltiplas necessidades. (MOURA, 1996, p.01)

De forma geral, podemos afirmar que os conceitos matemáticos produzidos pela humanidade surgiram da necessidade de sobrevivência e de preservação da espécie. O desenvolvimento humano esteve ligado ao trabalho de suprir as necessidades básicas de sobrevivência. Possibilitando desse modo, a criação e a apropriação de diversas ferramentas, sendo uma delas a matemática, que facilitaram o trabalho do homem ao longo da sua história.

O desenvolvimento das antigas civilizações e do próprio ser humano viabilizou a criação de símbolos para facilitar a necessidade de contar, no entanto, outras imprescindibilidades ocorreram, como por exemplo, o medir. A necessidade de medir, assim como dos números, surgiu de uma necessidade real do homem. Conforme Heródoto citado por Caraça (1989) ao descrever o surgimento da geometria:

Disseram-me que este rei (Sesóstris) tinha repartido todo o Egito entre os egípcios, e que tinha dado a cada um uma porção igual e retangular de terra, com a obrigação de pagar por ano um certo tributo. Que se a porção de algum fosse diminuída pelo rio (Nilo), ele fosse procurar o rei e lhe expusesse o que tinha acontecido à sua terra. Que ao mesmo tempo o rei enviava medidores ao local e fazia medir a terra, a fim de saber de quanto ela estava diminuída e de só fazer pagar o tributo conforme o que tivesse ficado de terra. Eu creio que foi daí que nasceu a Geometria e que depois ela passou aos gregos. (HERÓDOTO apud CARAÇA, 1989, p. 32)

Como descrito sobre o nascimento da geometria, podemos identificar a necessidade de medir, pois medir e contar são ações presentes no cotidiano dos sujeitos. Reportando a situação narrada por Heródoto, a contagem numérica já não era suficiente para quantificar a divisão de terras egípcias. Reparemos na seguinte questão: De que forma a distribuição das terras do Egito foi realizada, uma vez que todos tinham que ficar com a mesma porção de terra para pagar seus tributos, considerando a inexistência de instrumentos de medida que conhecemos na atualidade? 
Inicialmente o homem utilizava partes do próprio corpo para medir, tais como palmo, pés, braçada, que causava situações arbitrárias, incoerência e variáveis que só o contexto podia indicar a sua precisão - já que as partes do corpo tem variação de tamanho - então, chegaram à conclusão que deveriam estabelecer uma unidade de medida (padrão) e utilizaram, no primeiro momento, as partes do corpo do Faraó para estabelecer a padronização. Para medir os terrenos, como na passagem do Faraó Sesóstris narrado por Heródoto, os agrimensores utilizavam a corda como instrumento de medida e faziam a demarcação com nós periódicos, contendo a unidade de medida estabelecida - a medida do cúbito ${ }^{2}$ do Faraó estirava-se a corda e contavam quantas vezes o cúbito cabia no comprimento do terreno.

Para Caraça (1989, p. 29), medir é "comparar duas grandezas da mesma espécie, dois comprimentos, dois pesos, dois volumes, etc.". De acordo com esta definição podemos dizer que para realizarmos uma medida, ou seja, para compararmos duas grandezas de mesma natureza precisamos estabelecer alguns critérios. Em primeiro lugar é preciso estabelecer qual é a unidade de medida e o melhor instrumento de medida para realizar a medição. No exemplo dado, fica inviável medir o terreno do Egito utilizando a polegada do faraó, portanto, utilizaram como unidade de medida o cúbito e como instrumento a corda com nós. Segundo Moretti e Dias (2011, p. 120) "a criação do instrumento depende da grandeza que mede e tem que ser da mesma grandeza a ser medida".

Para medir então, é necessário estabelecer a unidade de medida e identificar quantas vezes esta unidade, grandeza, cabe dentro do que se quer medir.

Porém, podemos ter um caso de medida, como o exemplo dado da divisão das terras do Egito, onde a unidade de medida estabelecida não cabe de forma inteira no terreno, sobra ou falta um pedaço menor do que a grandeza estabelecida. Nesse caso, o que fazer? O enfrentamento desse conflito foi decisivo para se reconhecer que o campo dos números inteiros é insuficiente para medir grandezas contínuas, sendo necessária sua ampliação, criando-se então a subunidade (MORETTI; SOUZA, 2010).

A partir da necessidade humana de subdividir a unidade de medida estabelecida, estabelecese a limitação do campo numérico dos naturais e surge a necessidade de sua expansão com o campo numérico dos racionais, que inclui as representações fracionárias. Segundo Roxo (1928 apud ROSA, 2013b, p. 235) "fração é a medida de uma grandeza que contém uma ou mais das partes iguais em que se dividiu a unidade".

Essa relação entre a História da Medida e o surgimento das frações apresenta-se como um dos elementos centrais para o ensino de fração - A síntese histórica do conceito (MOURA, 1996) processo de ensino e de aprendizagem que evidencia quais os elementos essenciais do conceito que deve ser ensinado, um dos componentes estruturantes da proposta teórica-metodológica da Atividade Orientadora de Ensino.

\section{A PESQUISA EM MOVIMENTO}

Como afirma Vigotski (2001, p.86) "é somente em movimento que um corpo mostra o que é". Como procedimento metodológico de pesquisa isso implica criar condições que permitam ao pesquisador analisar o processo de desenvolvimento do seu objeto de estudo. Com esse objetivo, a investigação que desenvolvemos ocorreu na forma de um curso de extensão voltado à formação continuada de professores dos anos iniciais da educação básica, mas especificamente dos quarto e quinto anos do Ensino Fundamental. Tal curso denominado "O conceito de Fração e a organização do ensino a partir de Atividades Orientadoras de Ensino" foi desenvolvido em escola da rede municipal de Guarulhos, composto por quinze encontros semanais durante o segundo semestre de 2015.

Os quinze encontros do curso ocorreram durante o horário de trabalho dos professores, no espaço denominado hora-atividade que é destinado a momentos de planejamento e estudo. As discussões que se deram durante esse processo entre os professores e entre professores e pesquisadora, foram gravadas em áudio e vídeo. Tais gravações foram transcritas e, juntamente com as notas do diário de campo da pesquisadora e os registros escritos pelos participantes, constituíram-se dados para a análise. O grupo foi constituído por vinte professores do Ensino Fundamental, licenciados em Pedagogia, sendo: cinco professores dos primeiros anos, dois professores dos segundos anos, quatro professores dos quartos anos, cinco professores dos quintos anos, três professores da educação infantil e a professora coordenadora da unidade escolar. Apesar da diversidade de

2 O cúbito é a medida do cotovelo, antebraço, até a ponta do dedo médio. 
atuações dos professores que constituíram o grupo, a análise dos dados focou os professores que durante a realização da pesquisa lecionava no quarto ou quinto ano do Ensino Fundamental.

A organização do Curso apoiou-se nos pressupostos teóricos do conceito de Atividade (LEONTIEV, 1983) e de Atividade Orientadora de Ensino (MOURA, 1996), proporcionando condições para que os docentes trabalhassem coletivamente na produção de propostas de ensino que objetivassem as suas necessidades efetivas de ensino (MORETTI, 2007). Durante o curso, buscamos propor aos professores situações-problema que entendemos como desencadeadoras da aprendizagem docente, tendo como referência metodológica o experimento didático, que tem como base teórica os estudos de Vigotski e Davidov, apresentado por Moura e Cedro (2012) como um método de investigação que possibilita estudar a natureza do desenvolvimento psíquico dos sujeitos, o ensino e sua educação. Segundo esses autores, o experimento didático pode ser definido como:

[...] um método de investigação psicológica que permite estudar a essência das relações internas entre os diferentes procedimentos da educação e do ensino e o correspondente caráter de desenvolvimento psíquico do sujeito. Um dos pontos essenciais dessa perspectiva é que ela pressupõe a intervenção ativa do pesquisador nos processos psíquicos que ele estuda (MOURA; CEDRO, 2012, p.31).

No decorrer do experimento buscou-se acompanhar o movimento de transformação do pensamento empírico dos professores, o qual se apoia em caráter externo, imediato e suas representações são resultados da experiência sensorial (DAVIDOV, 1988), para o pensamento teórico que objetiva "em revelar a essência dos objetos, as leis internas de seu desenvolvimento" (DAVIDOV, 1988, p.106). Compreendendo esse como um processo de superação, no qual o pensamento empírico não deixa de existir, necessariamente. As ações da pesquisadora no decorrer do experimento didático buscaram criar condições para o desenvolvimento das características do pensamento teórico o qual, como afirma Davidov (1988),

[...] se esforça para passar da descrição dos fenômenos ao descobrimento da essência, da conexão interna dos mesmos. Sabe-se que a essência tem um conteúdo diferente dos fenômenos e das propriedades dos objetos diretamente dados. (DAVIDOV, 1988, p. 104)

Consideramos que o movimento de desenvolvimento do pensamento teórico, compõe um elemento central a ser investigado no processo de aprendizagem de todos os atores envolvidos nessa pesquisa: pesquisadora e professores que ensinam matemática no quarto e quinto anos do ensino fundamental.

\subsection{Metodologia de análise}

Com a intenção de evidenciar a relação entre o desenvolvimento do pensamento teórico de professores e a organização do ensino apoiamo-nos no método histórico-dialético cuja característica principal "é a de que o fenômeno estudado deve ser apresentado de tal modo que permita a sua apreensão em sua totalidade" (CEDRO, 2008, p.96). A busca por preservar a totalidade da unidade nos leva a compreendermos que,

Ao assumirmos as unidades estamos considerando-as como um elemento que explicita a regularidade do pensamento, o atuar sobre a complexidade da realidade e não como uma concepção desta. (MOURA, 2000, p.81)

Caraça (2002) denominou esse recorte da realidade de isolado, sendo "um conjunto de seres e fatos abstraindo de todos os outros que com eles estão relacionados. Uma secção da realidade, nela recortada arbitrariamente" (CARAÇA, 2002, p.105). Cedro (2008) especifica que "a ideia de isolado surge como uma ferramenta metodológica de análise, uma vez que, sabendo da impossibilidade de compreender de uma só vez a totalidade das relações, faz-se um recorte da realidade". (CEDRO, 2008, p. 112, grifo do autor). Segundo Caraça (2002), esse recorte faz-se necessário para que compreenda nele todos os fatores importantes e relevantes para o fenômeno estudado. O isolado apresenta-se como uma seção da realidade que conserva "todos os fatores 
que, ao se interdependerem, têm influência marcante no fenômeno a estudar" (MOURA, 2004, p. 267). Desse modo, o isolado abrange as propriedades do todo, sendo isolado para o estudo, mas integrante da sua totalidade pesquisada. Por esse motivo, optamos por trabalhar com os conceitos de Isolado e episódio na análise dos dados da pesquisa.

O isolado, nessa pesquisa, é constituído por episódios e compreendido como modos de focar as ações de aprendizagem docente no processo formativo e sua relação com a organização do ensino. Os episódios, por sua vez, são constituídos por um conjunto de cenas, que são selecionadas dentre os dados coletados com o intuito de revelar as ações da aprendizagem docente no processo de mudança na qualidade do pensamento: pensamento empírico para a aproximação do desenvolvimento do pensamento teórico, o que revela o movimento do conhecimento do professor sobre o conceito de fração,

Uma vez que, como já indicado, optou-se por priorizar na análise os participantes que estivessem, naquele ano, trabalhando com os educandos dos quartos e quintos anos do ensino fundamental, foram tomados para análise os dados obtidos junto a nove professores, sendo que quatro lecionavam para os educandos dos quartos anos e cinco para os quintos anos. Considerando os diversos momentos da coleta de dados e os diferentes instrumentos utilizados, organizamos a análise dos dados tendo como referência o nome fictício do professor, ano que estava lecionando, o encontro no qual foi coletada a informação e a indicação da fonte do dado utilizado, por exemplo, (Cleo, profa. $4^{\circ}$ ano, E-1, $\square$ ) para nos referirmos às informações obtidas da professora Cleo que lecionava para turma do quarto ano, durante o primeiro encontro e tendo como fonte do dado a transcrição de gravação audiovisual.

Quadro 1 - Fonte de dados coletados

\begin{tabular}{|l|l|}
\hline Símbolos & Fonte de dados coletados \\
\hline 0 & Transcrição da gravação audiovisual \\
\hline F & $\begin{array}{l}\text { Folha de registro coletivo para a resolução da } \\
\text { AOE }\end{array}$ \\
\hline Diário de campo & \\
\hline
\end{tabular}

Fonte: Zeferino (2016)

A seguir na seção 4. Isolado - Análise, Reflexão e planificação das ações: Indícios da formação do pensamento teórico, utilizamos como referência o quadro 1, descrito acima, para indicar a fonte dos dados e permitir uma maior compreensão do movimento da pesquisa.

4 DESENVOLVIMENTO DO PENSAMENTO TEÓRICO SOBRE FRAÇÃO: conhecimento e prática em movimento

Para os fins desse texto, selecionamos dentre os episódios analisados o que denominamos "Análise, Reflexão e planificação das ações: Indícios da formação do pensamento teórico" por compreendermos que ele explicita a relação entre o desenvolvimento do pensamento teórico sobre frações, o conhecimento teórico do professor e a forma como ele planeja e organiza o ensino sobre esse conceito. Para isso, destacaremos alguns movimentos de formação do pensamento teórico reflexivo e analítico - que foram se tornando mais evidentes a partir do sétimo encontro. Movimentos que evidenciam o que os estudos de Davidov (1988) e a investigação de Ribeiro (2011) denominam tomada de consciência, identificação e compreensão dos elementos que constituem o conceito estudado e sobre suas ações de ensino.

Começamos trazendo a fala do professor Leo que no encontro 11 apresenta indícios de um movimento reflexivo e analítico sobre o ensino do conceito, ao tomar consciência do conceito de fração nos "limites do visual empírico" e tenta justificar o porquê de se utilizar a barra de chocolate e a figura da pizza: 
Eu acho que não favorece começar com a parte teórica, quando se chama as partes da fração de denominador e numerador, fração própria, fração imprópria; quando vai falar de fração equivalente, isso é complicado, é uma parte muito teórica. (Leo prof. $4^{\circ}$ ano, $\mathrm{E}-11, \square$ )

Em sua fala, o termo "teórica" não está relacionado ao conhecimento científico do conceito e sim à identificação de nomenclaturas relacionadas às frações. O professor demonstra em sua fala, que o ensino apenas ancorado na utilização de nomenclaturas e definições superficiais, dificulta a compreensão em sua integridade conceitual, confirmando o que Lopes (2008) aponta como um grave problema relacionado ao ensino desse conceito, "Não faz sentido gastar tempo produtivo das aulas com definições desse tipo. Falar de frações aparentes e até mesmo de frações impróprias, tão logo se está introduzindo as ideias sobre frações é um atentado à intuição do aluno." (LOPES, 2008, p. 4).

Ao final do depoimento do professor Leo, outras professoras se posicionaram trazendo para o debate mais elementos reflexivos e analíticos sobre o modo geral de organização do ensino do conceito de fração:

Eu acho que acaba ficando muito pela decoração, saber que embaixo é o denominador e em cima o numerador. Como a gente falou no outro encontro, fração, ler fração, utilizar fração não é uma coisa comum, não faz parte da nossa vida. (Ana profa. $5^{\circ}$ ano, $\mathrm{E}-11, \square$ )

Em seguida, outra professora do grupo, não se sentiu contemplada pela fala do colega, que tenta apresentar e justificar o ensino de fração baseado apenas no visual empírico. Ela manifesta a sua opinião sobre o ensino do conceito:

Eu acho que não favorece o ensino... Aquela famosa pizza que vem no livro que a gente fica colando e copiando em outras partes. Eu acho que fica maçante e não favorece, já estou cansada disso. (Nina profa. $5^{\circ}$ ano, $\mathrm{E}-11, \square$ )

Aqui a professora Nina, demonstra uma inquietação em relação à organização do ensino do conceito de fração ancorado nas características do pensamento empírico, ao manifestar que apenas a representação de figuras e situações que envolvem a concepção parte/todo e sua quantificação discreta, não favorecem o ensino do conceito. Esse momento de análise aponta mudanças no tipo de pensamento, do pensamento empírico ao pensamento teórico, pois demostra o seu distanciamento em relação à proposta elaborada e apresentada no sétimo encontro, onde na ocasião, ela havia considerado como uma proposta adequada iniciar o conceito de fração "utilizando a repartição de um alimento".

Nesse diálogo, é possível analisar que o grupo depara-se com a necessidade que o coloca em movimento, no caso a superação da quantificação discreta como estratégia de ensino de frações. Nesse sentido, a necessidade se materializa no novo objeto, tornando-o motivo da nova atividade de ensino, o que reitera a estrutura da atividade que Leontiev (1978) preconiza em seu estudo. Também, os docentes manifestam traços de desenvolvimento de novo tipo de pensamento, aproximando-se do pensamento teórico. Conforme Rubtsov (1996) a elaboração o conhecimento teórico se apresenta "por meio de uma análise do papel e da função de uma certa relação entre as coisas no interior de um sistema" (CEDRO; MORAES; ROSA, 2010, p. 77). Dessa forma, o grupo demonstra a necessidade de ampliar o conhecimento sobre o conceito de fração para que possa propor situações desencadeadoras de aprendizagem sobre o conceito que superem a abordagem empírica.

No mesmo encontro, a professora Ana apresenta o movimento reflexivo sobre a sua prática e manifesta as dificuldades que enfrentou ao trabalhar uma proposta do livro didático sobre o conceito de fração:

[...] momento desabafo: eu fui trabalhar com eles [alunos] o exercício de reta numérica... Eu achava: uma retinha numérica vou saber fazer, vou passar, depois faço a correção e tá tudo certo. Gente... Oh, sufoco! Porque eu expliquei de um jeito sem olhar a resposta e quando eu olho lá, ela não estava contando tudo, (...) só depois que eu fiz essa atividade com eles que eu fui olhar a resposta e eu vi que não era, só que eu não sabia explicar o jeito do livro. (...) Porque eu nunca tinha visto fração numa reta, eu 
nunca tinha associado que o milimetro era uma fração da medida. É difícil para gente explicar essas coisas minuciosas se a gente não sabe o processo. (Ana, profa. $5^{\circ}$ ano, $\mathrm{E}-11, \square$ )

Podemos analisar nesse relato que a professora Ana apresentava indícios de um pensamento empírico sobre o conceito de fração uma vez que sua compreensão sobre o conceito estava centrada apenas nas peculiaridades do concreto (DAVIDOV, 1982; 1988). Como destacam Cedro, Moraes e Rosa (2010)

O pensamento empírico possibilita ao sujeito uma atividade cognitiva que the assegure a separação dos atributos dos objetos ou fenômenos e sua designação, incluindo aí aqueles que em determinado momento não são possíveis de serem observados e que somente podem ser conhecidos por meio de deduções. (CEDRO; MORAES; ROSA, 2010, p. 73).

O relato da professora Ana também demonstra a dificuldade em compreender as frações como uma possível representação dos números racionais. No entanto, só lhe foi possível compreender essa relação quando os professores ultrapassaram o pensamento empírico sobre o conceito de fração e caminharam em direção ao pensamento teórico, observando dessa forma que a fração está além da sua representação geométrica.

A professora Ana continua o seu relato demonstrando o movimento reflexivo e analítico característico do pensamento teórico:

Ai... eu vi que a aula acabou e eles estavam com um enorme ponto de interrogação, porque eu falei uma resposta que nem eu tinha entendido direito. Então, preciso retomar e diminuir o prejuízo. (Ana profa. $5^{\circ}$ ano, $\mathrm{E}-11, \square$ )

A professora Ana evidencia a importância de conhecer o conceito para a organização de situações de ensino, pois percebe que ao ensinar o conceito de fração a partir de exemplos particulares (característica do pensamento empírico), não se consegue explicar o conceito em seu caráter geral, de modo a compreendê-lo e utilizá-lo em diferentes situações (característica do pensamento teórico).

A partir do depoimento da professora surgiu no grupo a necessidade de elaborar uma situação desencadeadora de aprendizagem sobre o conceito de fração e a sua localização na reta numérica. Essa situação constituiu o movimento de planificação das ações manifestando assim, indícios da formação do pensamento teórico dos professores participantes da pesquisa, objetivado em nova prática docente. Assim, conforme, registro no diário de campo da pesquisadora,

[...] os professores se identificaram com o "desabafo" da professora Ana sobre a dificuldade de compreender a fração como número racional, e combinaram para o próximo encontro pensar em uma proposta de ação para ser desenvolvida com os estudantes. (Pesquisadora, $\mathrm{E}-11, \square$ ).

Durante o movimento de planificação das ações, por meio da proposição de novas práticas, foram apresentadas pelos professores três sugestões:

Figura 1 - Proposta - 1 (Ana e Rita, profa. $5^{\circ}$ ano, E - 13 83 3 )

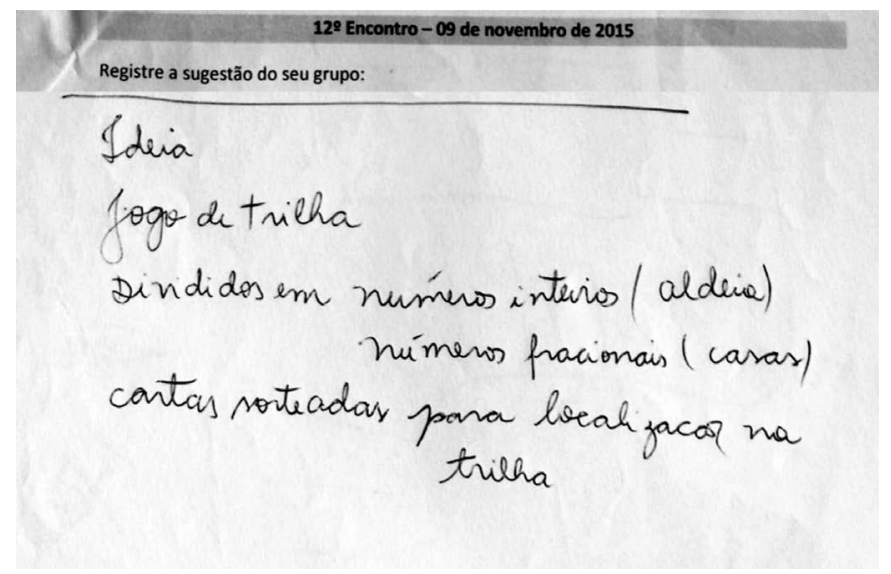

Fonte: Zeferino (2016) 
Figura 2 - Proposta - 2. (Cleo e Rute, profa. $4^{\circ}$ ano, E - 13, $\Omega^{\beta} \beta$ )

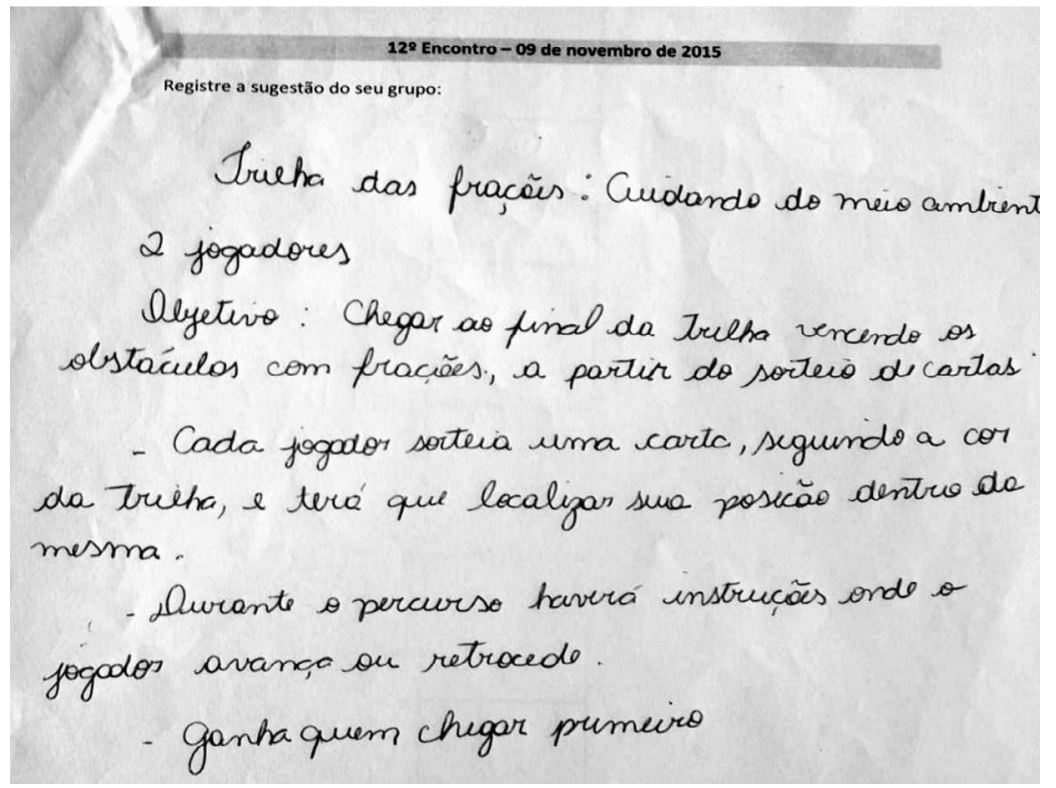

Fonte: Zeferino (2016)

As sugestões de situações desencadeadoras de aprendizagem observadas na Proposta 1 e 2 elaboradas pelos professores utilizaram como recurso metodológico o jogo e tinham como objetivo apresentar aos estudantes situações de ordenação e localização dos números fracionários na reta numérica, a partir de um jogo de trilha. No entanto, quando as professoras Cleo e Rute socializaram o jogo que denominaram "Trilha das frações: Cuidando do meio ambiente", conforme registro da proposta (figura 02), perceberam que essa proposta não atenderia o objetivo de apresentar a relação da fração com o seu significado aritmético. Pois, conforme descrição do jogo "cada jogador sorteia uma carta [contendo a escrita de uma fração], seguindo a cor da trilha, e terá que localizar sua posição dentro da mesma.", dessa forma o participante só teria a necessidade de contar os espaços que compõe a trilha, reincidindo na situação de quantificação discreta. Por esse motivo essas propostas foram refugadas pelo grupo.

A terceira proposta, elaborada pelas professoras Nina e Cida, também passou pela problematização acerca da situação de quantificação discreta, presentes nas propostas anteriormente apresentadas:

Figura 3 - Proposta - 3. (Nina e Cida, profa. $5^{\circ}$ ano, E - 13, $3^{\beta} \beta$ ).

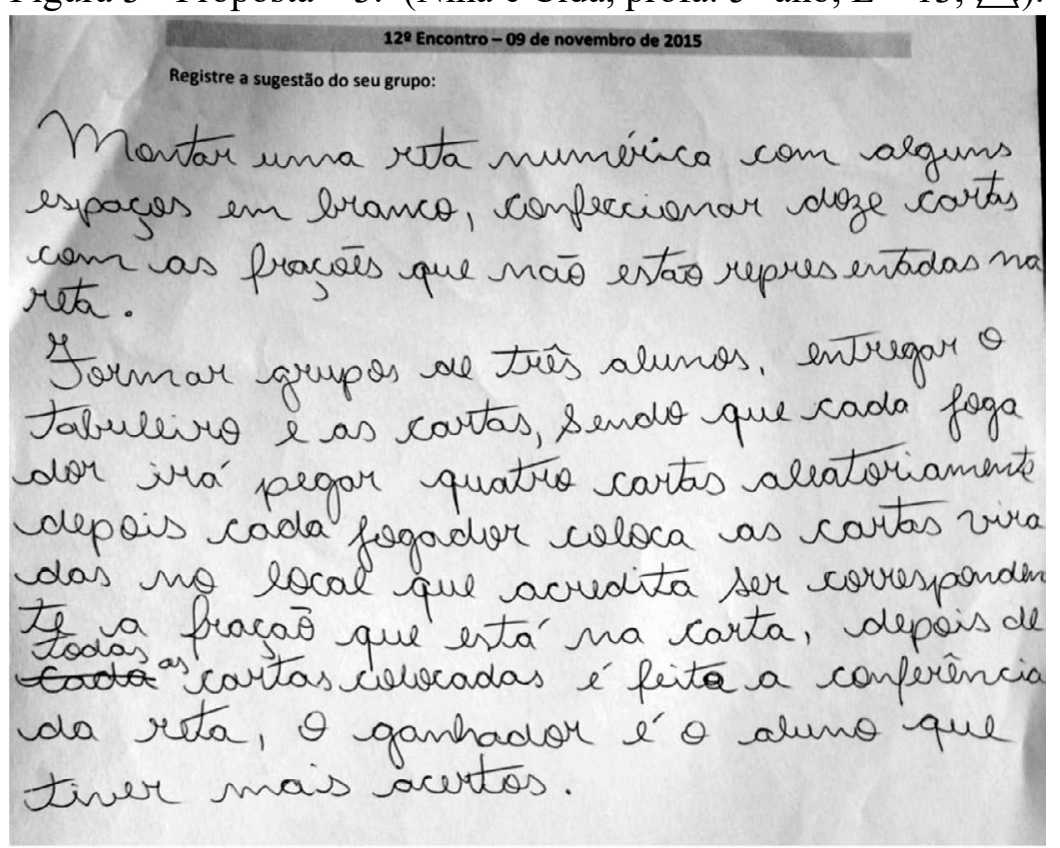

Fonte: ZEFERINO (2016) 
Como podemos observar, a proposta elaborada pelas professoras Nina e Cida (figura 03) apresenta um jogo cujo objetivo era proporcionar aos estudantes a compreensão que o conjunto dos números racionais é uma extensão do conjunto dos naturais, para isso foi proposto um tabuleiro com o formato de uma reta numérica e algumas cartas que apresentavam números racionais em representação fracionária. Tais cartas seriam usadas para preencher os "espaços em branco", marcações da reta numérica projetada no tabuleiro do jogo. Essa proposta foi escolhida pelo grupo para ser desenvolvida com as turmas do quarto e quinto ano do ensino fundamental.

Durante a elaboração de situações desencadeadoras de aprendizagem foi possível identificar indícios do movimento de superação do pensamento empírico para o desenvolvimento do pensamento teórico, o qual foi se constituindo no decorrer da pesquisa, principalmente, quando os professores se depararam com a necessidade de organizar o ensino do conceito de fração. Assim, a elaboração de nova prática pedagógica para o ensino de frações nos permite estabelecer a relação com o estágio de constituição do pensamento teórico, denominado por Davidov (1988) como planificação das ações, movimento que demonstrou a ampliação do conhecimento dos professores sobre o conceito das frações. Tal fato pode ser observado a partir da comparação entre as novas práticas e as primeiras propostas elaboradas pelos professores durante o $7^{\circ}$ encontro, no qual foi possível verificar que os professores naquele momento baseavam o ensino das frações nas características visuais. Já no $13^{\circ}$ encontro, as propostas apresentadas pelos professores, passaram a explicitam algumas propriedades mais complexa do conceito, como a relação entre o geral (sistema de numeração) e o particular (as frações), na representação da reta numérica.

Com intuito de mobilizar o interesse das crianças, em participar do jogo, os professores utilizaram o recurso da histórica virtual baseado no livro "Como o mundo acorda", autor Ye shil Kim (2009).

Figura 04 - Jogo da reta numérica.
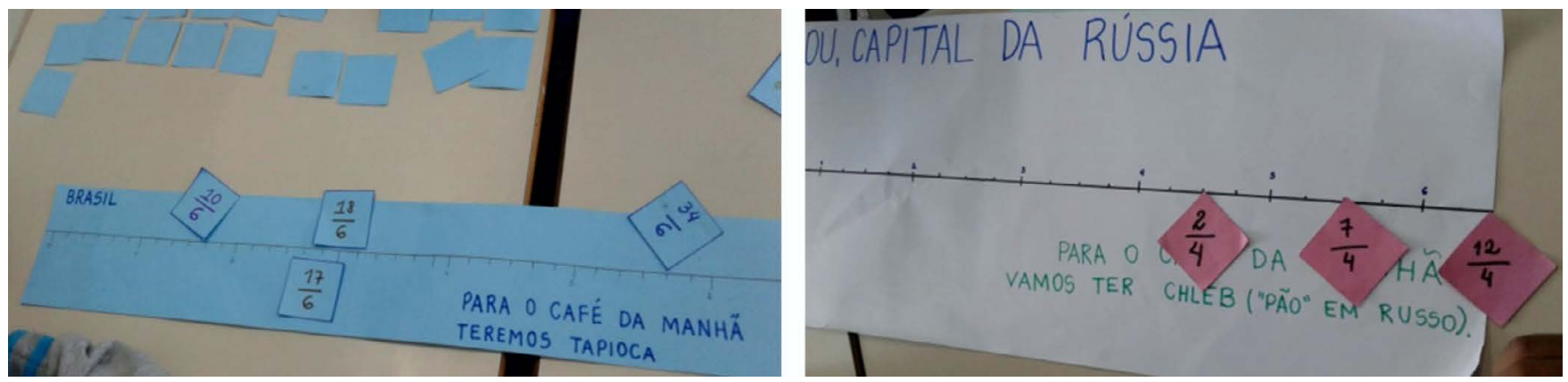

Fonte: Zeferino (2016)

No processo de elaboração da situação desencadeadora de aprendizagem, elaborada pelos participantes da pesquisa, a avaliação constitui-se como elemento inerente do planejamento e realização da atividade (MOURA, 2010). Este processo avaliativo esteve presente durante o processo de planificação das ações, mais especificamente nos seguintes momentos: no final da confecção do jogo, na escolha da história virtual e na produção dos cartões contendo as frações. Tal processo avaliativo permitiu aos professores verificaram se a proposta atendia aos objetivos estabelecidos inicialmente, como podemos perceber na análise da professora Rita:

Olha... Se deixarmos com essas marcações [das subunidades da reta numérica] as crianças vão apenas contar os tracinhos, esse não é o nosso objetivo. O que podemos fazer? (Rita, profa. $5^{\circ}$ ano, E -14, $\square$ )

A avaliação apresentada pela professora Rita mobilizou o grupo a discutir e reelaborar a proposta do jogo, entrando em um momento de análise e reflexão coletiva, acerca do planejamento da situação desencadeadora de aprendizagem. Como resultado, a professora Nina apresenta uma sugestão para o grupo:

Podemos tirar as marcações do tabuleiro do jogo, deixar que os alunos a partir da leitura dos cartões [contendo a fração] estabeleçam as subunidades. (Nina, profa. $5^{\circ}$ ano, E -14, $\square$ ) 
Os professores consideraram pertinente a sugestão da professora Nina e realizaram as alterações necessárias. Desse modo, evidenciaram que o movimento de transformação do pensamento e a apropriação de novo conhecimento ocorre a partir da compreensão da existência de necessidades que surgem não somente da observação, mas de uma análise sistêmica do fenômeno e, por sua vez, implica na constituição de nova prática. Assim, a prática constitu-se em unidade dialética com a teoria, no caso analisado, a apropriação de conhecimento teórico.

A planificação das ações que resultou na elaboração da situação desencadeadora de aprendizagem denominada "Jogo da reta numérica" descrita anteriormente, teve por objetivo evidenciar a fração como uma representação dos números racionais, bem como a superação da quantificação discreta para a compreensão da quantificação contínua que é própria do conceito. O momento de planificação das ações foi evidenciado quando os professores perceberam que planejar situações desencadeadoras de aprendizagem sobre esse conceito envolve a necessidade de compreender que o desenvolvimento do conceito de fração deve partir da sua base teórica histórica e relaciona-se ao seu significado genuinamente científico (DAVIDOV, 1982).

$\mathrm{Na}$ avaliação final do experimento didático, que ocorreu no décimo quinto encontro, foi possível observar indícios dessa transformação:

Eu tinha dado o exercício da reta numérica do livro, logo no começo do curso, eu lembro que nas primeiras aulas eu falei que tinha me atrapalhado toda. E depois do curso, aplicando o jogo eu consegui explicar, porque eu estava entendendo.

Porque na primeira reta eles [os educandos] perguntavam, eu respondia, eles perguntavam de novo eu respondia e não sabia mais se estava respondendo certo, eu estava me atrapalhando.

[...] E depois clareou muito, eu consegui explicar o jogo com domínio. (Ana profa. $5^{\circ}$ ano, E -15, $\square$ )

A professora Rita, concorda com a professora Ana e completa:

Porque conforme foi passando, a gente foi realizando as atividades, estudamos e foi clareando as ideias. Eu acho que a sequência do curso fez diferença para a gente entender. (Rita profa. $5^{\circ}$ ano, E $-15, \square)$

É possível notar que há uma compreensão de que o processo de apropriação do conhecimento científico, sobre o conceito de fração, deve estar presente na organização do ensino, pois a forma e o conteúdo são indissociáveis do objeto de estudo. Os depoimentos, acima e os que serão transcritos a seguir, explicitam que as professoras reconhecem as fragilidades que possuíam em relação à compreensão do conceito de fração.

Tinha coisa que eu nem sabia, agora eu sei. (Rute profa. $5^{\circ}$ ano, E -15, $\square$ )

A professora Ana reconhece que muitas das fragilidades dos docentes sobre os conceitos, especialmente os de matemática, têm a sua origem na formação inicial:

Quando aprendemos na faculdade, nem sempre explicam o conteúdo, explicam a metodologia. Quando aprendemos não era o entendimento do conceito... Não tivemos o entendimento do processo, fazíamos a conta mecanicamente, fazemos tudo mecanicamente e pronto. Mas, quando você se vê em sala de aula, que a gente tem que explicar o conceito, o processo para alguém, fica complicado... Porque você sabe fazer, mas não sabe explicar, então é difícil. (Ana profa. $5^{\circ}$ ano, E -15, $\square$ )

Como afirma Davidov (1982), o pensamento teórico é identificado na própria existência mediatizada, refletida e essencial do ser. Os indícios do desenvolvimento do pensamento teórico presentes nos relatos das professoras corroboram as afirmações de Davidov (1988) sobre a apropriação de conceitos:

Ter um conceito sobre um objeto significa saber reproduzir mentalmente seu conteúdo, construído. A ação mental de construção e transformação do objeto constitui o ato de sua compreensão e explicação, a descoberta de sua essência. (DAVIDOV, 1988, p. 126) 
A apropriação desse tipo de pensamento possibilita ao sujeito, condições para compreender e dar novos significados para o mundo que o cerca, permite a ele transformar a forma e o conteúdo do seu pensamento e, no caso do ensino, resulta em nova prática docente.

\section{CONSIDERAÇÕES FINAIS}

A pesquisa relatada buscou compreender possíveis relações entre a organização do ensino do conceito de número racional, na sua representação fracionária, e desenvolvimento do pensamento teórico do professor, ou mais especificamente, compreender como o conhecimento e a compreensão que o professor tem sobre o conceito de fração impacta a forma como esse professor organiza 0 seu ensino.

Os resultados da pesquisa nos permitiram reconhecer que a apropriação do conceito de fração (conteúdo) e a organização do ensino (forma) manifestam-se como elementos inerentes ao trabalho docente, e de forma mais específica a partir da nossa pesquisa, a atuação do professor que ensina matemática. Esse movimento da apropriação do conceito de fração e a organização do ensino estiveram presentes no desenvolvimento das situações desencadeadoras de aprendizagem que constituíram o experimento didático.

Destaca-se nesse processo, o conceito da Atividade Orientadora de Ensino que, ao ser adotado no experimento didático como proposta de organização da atividade de ensino e de aprendizagem, se mostrou como desencadeador da apropriação do conceito. Além disso, a AOE possibilitou relacionar o importante papel da organização do ensino no desenvolvimento do pensamento teórico no conceito da fração. O estudo de aspectos históricos e conceituais do conceito da fração foi essencial para a explicitação de elementos de sua essência e a superação da simples observação das propriedades aparentes e particulares do conceito, características do pensamento empírico.

Os dados obtidos na investigação apresentam indícios que a forma (organização do ensino) e o conteúdo (conhecimento científico do conceito) são elementos indissociáveis e elementares na atividade de ensino para constituição do pensamento teórico, pois o professor ao se apropriar de elementos do conhecimento científico (conteúdo), no caso o conceito teórico de fração, tem a possibilidade de transformar o pensamento empírico que tinha inicialmente para desenvolver 0 pensamento teórico na sua relação com o objeto de ensino e reorganizar sua prática.

A análise dos dados obtidos durante o experimento didático evidenciou que as práticas para o ensino do conceito de fração se limitavam inicialmente à quantificação discreta, não estabelecendo relação com a quantificação contínua e, desta forma, limitando a compreensão do conceito aos limites do pensamento empírico. O desenvolvimento de novos conhecimentos sobre o conceito se deu em um movimento de desenvolvimento do pensamento teórico diretamente relacionado à reflexão, análise e planificação das ações os quais, evidenciaram a tomada de consciência, identificação e compreensão dos elementos que constituem o conceito estudado e sobre suas ações de ensino (DAVIDOV, 1982; 1988).

Ao planificarem ações na elaboração do "Jogo da reta numérica" evidenciou-se a preocupação dos professores com a superação da quantificação discreta visando à compreensão da quantificação contínua. Nesse processo, os professores perceberam a necessidade de compreenderem o desenvolvimento do conceito de fração a partir da sua base teórica histórica, seu significado genuinamente científico (DAVIDOV, 1982), para a organização do ensino com vistas ao pensamento teórico. Ou seja, ao começar a pensar teoricamente sobre o conceito, o professor passa a ter como preocupação desenvolver o pensamento teórico de seus estudantes. Assim, foi possível notar que passou a haver uma compreensão de que o processo de apropriação do conhecimento científico sobre o conceito de fração deve estar presente na organização do ensino, pois a forma e conteúdo são vertentes do objeto de estudo.

Assim, os resultados dessa pesquisa reforçam que a aprendizagem docente pode resultar de uma constante busca mediada de novas ações que reflitam novas apropriações teóricas do professor na articulação entre a teoria e a prática na organização do ensino de matemática. Processo esse que ao mesmo tempo influencia e é influenciado pelo desenvolvimento do pensamento teórico do professor que ensina matemática. No trabalho docente, essa transformação se dá por meio da apropriação do conhecimento científico do conceito e na organização do ensino que passa a ser objetivada em novas práticas. 


\section{REFERÊNCIAS}

AMORIM, Gisele Mendes. Matemática na Educação Infantil? Contribuições da Atividade Orientadora de Ensino para a (re) organização da prática docente. Dissertação (Mestrado) - Universidade Federal de São Paulo, Programa de Pós Graduação em Educação, 2015.

BERNARDES, M. E. M. Mediação Simbólica na Atividade Pedagógica: Contribuições do Enfoque Histórico-Cultural para o Ensino e Aprendizagem. 2006. Tese (Doutorado) - Universidade de São Paulo, SP, 2006.

CARAÇA, B. de J. Conceitos Fundamentais da Matemática. 9 ed. Lisboa: Livraria Sá da Costa Editora, 1989.

. Conceitos fundamentais de matemática. 4 ed. Lisboa: Gradiva, 2002.

CATALANI, E. M. T. A inter-relação forma e conteúdo no desenvolvimento conceitual da fração - Dissertação (Mestrado) - Campinas, SP, 2002

CEDRO, W. L. O motivo e a atividade de aprendizagem do professor de Matemática: uma perspectiva histórico-cultural. 2008. Tese (Doutorado). Faculdade de Educação de Educação, Universidade de São Paulo, São Paulo, 2008.

CEDRO, W. L.; DE MORAES, S. P. G.; DA ROSA, J. E. A Atividade de Ensino e o Desenvolvimento do Pensamento Teórico em Matemática. Ciência \& Educação, v. 16, n. 2, p. 427-445, 2010.

DAVIDOV, V.V. La enseñanza escolar el desarrollo psíquico: investigación psicológica teórica y experimental. Moscú: Editorial Progreso, 1988.

Tipos de generalización em la enseñanza. Havana: Pueblo y Educación, 1982.

DIAS, M. S; MORETTI, V. D. Números e operações: elementos lógico-históricos para atividade de ensino. Curitiba: Ibpex, 2011.

ENGELS, F. Dialéctica da Natureza, Ed. Sociales, p. 171.1975.

ENGELS, Friedrich. Sobre o papel do trabalho na transformação do macaco em homem [1876]. In: ENGELS, Friedrich; MARX, Karl. Obras escolhidas. São Paulo: Alfa-Omega, s.d., v. II.

KIM, Y. S. Como o Mundo Acorda - Col. Tan Tan. Ed. Callis, 2009.
LEONTIEV, A. N. Actividad, consciência, personalidade. Ciudad de La Habana. Pueblo y Educación, 1983.

O desenvolvimento do psiquismo. Lisboa: Horizonte Universitário, 1978.

LOPES, A. J. O que nossos alunos podem estar deixando de aprender sobre frações, quando tentamos Ihes ensinar frações. Rio Claro: Bolema , p. 1-22, 2008.

MAGINA, Sandra; CAMPOS, Tânia. A fração nas perspectivas do professor e do aluno dos dois primeiros ciclos do ensino fundamental. Boletim de Educação Matemática, v. 21, n. 31, 2008.

MELLO, S. A.; LUGLE, A. M. C. Formação de Professores: Implicações Pedagógicas da Teoria Histórico-Cultural. Revista Contrapontos, v. 14, n. 2, p. 259-274, 2014.

MORAES, S. P. G. Avaliação do processo de ensino e aprendizagem em matemática: contribuições da teoria histórico-cultural. Tese (Doutorado em Educação: Ensino de Ciências e Matemática) - Universidade de São Paulo, SP, 2008.

MORETTI, V. D. Professores de Matemática em atividade de ensino: uma perspectiva histórico-cultural para a formação docente. 2007. 206 f. Tese (Doutorado em Educação: Ensino de Ciências e Matemática) - Universidade de São Paulo, SP, 2007.

MORETTI, V. D.; MOURA, M. De. O. Professores de Matemática em Atividade de Ensino: Contribuições da Perspectiva Histórico-Cultural para a Formação Docente. Ciência \& Educação, v. 17, n. 2, p. 435-450, 2011.

MOURA, M. O. (Coord.). Controle da variação de quantidades. Atividade de ensino. São Paulo: Universidade de São Paulo, 1996.

O educador matemático na coletividade de formação: uma experiência com a escola pública. 2000. Tese (Livre - Docência em Educação) - Universidade de São Paulo, São Paulo, 2000.

O. Pesquisa colaborativa: um foco na ação formativa. In: BARBOSA, R. L. (Org.). Trajetórias e perspectivas na formação de educadores. Marília -SP: Ed. Da Unesp, 2004.

(Org.). Atividade Pedagógica na Teoria Histórico-Cultural. Brasília-DF: Ed. Liber livros, 2010. 
MOURA, M. O.; CEDRO, W. L. Possibilidades Metodológicas na Pesquisa em Educação Matemática: o experimento didático. Educativa, v. 15, n. 1, p. 2538, 2012.

RIBEIRO, F.D. A aprendizagem da docência na prática de ensino e no estágio: contribuições da Teoria da Atividade. 2011. Tese (Doutorado) - Faculdade de Educação da Universidade de São Paulo, SP, 2011.

RIGON, A. J.; ASBHAR, F. S. F.; MORETTI, V. D. Sobre o Processo de Humanização. In: MOURA, M. O. (Org.). Atividade Pedagógica na Teoria HistóricoCultural. Brasília-DF: Ed. Liber livros, 2010.

ROSA, J. E. Proposições de Davydov para o ensino de matemática no primeiro ano escolar: inter-relações dos sistemas de significações numéricas. 2012. 244 f. Tese (Doutorado em Educação) - Universidade Federal do Paraná, Curitiba, 2012.

ROSA, J. E. et al. Movimento do Conhecimento Matemático na História Virtual Verdim e seus Amigos. Perspectivas da Educação Matemática, v. 06, p. 2141, 2013a.

Relações entre as proposições para o ensino do conceito de fração com base no ensino tradicional e na Teoria Histórico-Cultural. REVEMAT. Florianópolis (SC), v.08, Ed. Especial (dez.), p. 227245, 2013b.

RUBTSOV, V. A atividade de aprendizado e os problemas referentes à formação do pensamento teórico dos escolares. In: GARNIER, C.; BERDNARZ, N.; ULANOVSKAYA, I. (Org.). Após Vygotsky e Piaget: perspectivas sociais e construtivista esco- las russa e ocidental. Porto Alegre: Artes Médicas, 1996.

SOUZA, M. G. O. de; RESENDE, M. R. O Papel do docente e das instituições educativas: Um estudo na perspectiva Histórico-Cultural. Revista Encontro de Formação de Professores. Uberaba, v. 1, n. 1, p. 1- 7, 2013.

VIGOTSKI, Lev. S. Pensamento e palavra. In: A construção do pensamento e da linguagem. (Trad. Paulo Bezerra). São Paulo: Martins Fontes, 2001.

A formação social da mente. 6. Ed. São Paulo: Martins Fontes, 2004.

A formação social da mente: o desenvolvimento dos processos psicológicos superiores. IN: VIGOTSKY, L.S.; organização Michael Cole...[et al.] tradução José cipolla Neto, Luis Silveira Menna Barreto, Solange astro Afeche - 7ed. São Paulo: Martins Fontes, 2007.

A construção do pensamento e da linguagem; Tradução Paulo Bezerra. - 2a . Ed./ $3^{\mathrm{a}}$. Tiragem - São Paulo: Editora WMF Martins Fontes, 2010.

ZEFERINO, L. C. Aprender A Ensinar Frações A Partir Do Conceito De Atividade Orientadora De Ensino: Um Estudo Com Professores De Quartos E Quintos Anos Do Ensino Fundamental. Dissertação (mestrado) - Universidade Federal de São Paulo, Programa de Pós-Graduação em Educação, 2016. 